Int. J. Dev. Biol. 48: 935-945 (2004)

doi: $10.1387 / \mathrm{ijdb} .041873 \mathrm{pr}$

\title{
A moving wave patterns the cone photoreceptor mosaic array in the zebrafish retina
}

\author{
PAMELA A. RAYMOND* and LINDA K. BARTHEL \\ Department of Cell \& Developmental Biology, University of Michigan Medical School, Ann Arbor, MI, USA
}

\begin{abstract}
In this paper, we describe the embryonic origin and patterning of the planar mosaic array of cone photoreceptor spectral subtypes in the zebrafish retina. A discussion of possible molecular mechanisms that might generate the cone mosaic array considers but discards a model that accounts for formation of neuronal mosaics in the inner retina and discusses limitations of mathematical simulations that reproduce the zebrafish cone mosaic pattern. The formation and organization of photoreceptors in the ommatidia of the compound eye of Drosophila is compared with similar features in the developing zebrafish cone mosaic, and a model is proposed that invokes spatiotemporally coordinated cell-cell interactions among cone progenitors to determine the identity and positioning of cone spectral subtypes.
\end{abstract}

KEY WORDS: pattern formation, retinal development, cell fate, opsin gene, visual pigment

\section{Cone photoreceptors in zebrafish are organized in a precise mosaic array}

Photoreceptors are highly specialized neurons with unique, differentiated features associated with detection of light and transduction of neural signals (Cohen, 1972; Dowling, 1987). The identity, distribution, and spacing of individual photoreceptor subtypes is an important developmental parameter that influences many properties of visual function, including the ability to detect stimuli over a large range of light intensities, define the limits visual acuity, mediate color vision, etc. Most vertebrates have multiple spectral subtypes of cone photoreceptors as well as a single type of rod photoreceptor. The predominant animal models used to investigate photoreceptor differentiation and maintenance are rodents, which have strongly rod-dominant retinas, so we know much more about the developmental mechanisms involved in formation of rod photoreceptors (Morrow etal., 1998; Cepko, 1999; Levine et al., 2000; Livesey and Cepko, 2001) and relatively less about cone photoreceptor development (Adler, 2000). Although the human retina is rod-dominant in the periphery of the retina, the macula, which is most critical for functional vision, is strongly conedominant. Thus, the failure of cone photoreceptors to develop properly or the subsequent loss of cone function in humans has the most severe consequences on visual abilities (Neitz and Neitz, 2000; Aiello, 2003; Ambati et al., 2003; Pacione et al., 2003).

Cone photoreceptor development has been studied in a few animal models that have abundant cones in addition to rod photoreceptors, most notably primates (Bumsted et al., 1997; Sears etal., 2000), chicks (Bruhn and Cepko, 1996; Adler etal., 2001), and teleost fishes (Branchek and BreMiller, 1984; Larison and BreMiller, 1990; Raymond et al., 1995; Schmitt and Dowling, 1996). Unlike rod photoreceptors, which except in some amphibians (Rohlich and Szel, 2000) all express the same visual pigment gene (rod opsin or rhodopsin), differentsubtypes of cone photoreceptors express different cone opsin genes that generate visual pigments with varying spectral absorption maxima (Yokoyama, 2000; Cook and Desplan, 2001; Ebrey and Koutalos, 2001). Cone photoreceptors in the adultzebrafish retina include four spectral subtypes, each of which expresses a specific opsin gene that produces a visual pigment with maximum photon absorption at a wavelength approximately corresponding to red (long), green (medium), blue (short), orultraviolet (UV), respectively (Nawrocki et al., 1985; Raymond et al., 1993; Vihtelic et al., 1999; Chinen et al., 2003) (Table 1). Each spectral cone subtype also has a distinctive cellular morphology: the UV cones are very short, the blue cones are longer, and the green and red cones are the longest and are fused to form double cone pairs (Fig. 1). The cone outer segments are therefore segregated by spectral subtype into discrete, vertical layers, although their somata and nuclei form a monolayer within the plane of the apical surface (called the outer limiting membrane of the retina).

The cone photoreceptors in the zebrafish retina, as in many other teleost fish species (Lyall, 1957; Engström, 1960; Engström, 1963; Ahlbert, 1968; Nishiwaki et al., 1997), are arranged in a precise, two-

Abbreviations used in this paper: NND, nearest neighbor distance.

\footnotetext{
*Address correspondence to: Dr. Pamela A. Raymond. Department of Cell \& Developmental Biology, University of Michigan Medical School, 5814 Medical Sciences II Building, Ann Arbor, MI 48109-0616, USA. Fax: +1-734-763-1166. e-mail: praymond@umich.edu
} 


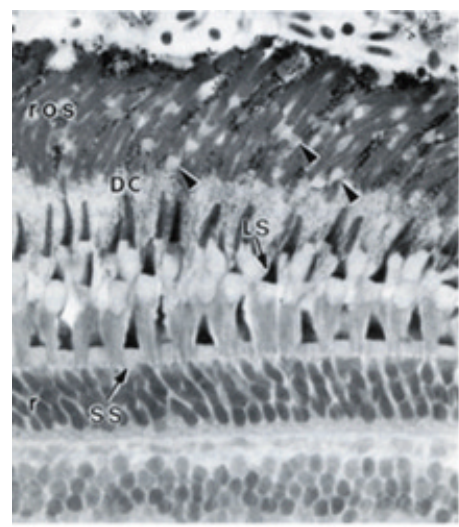

Double in situ hybridization with blue opsin (Fast Red) and UV opsin (TSA-FITC) RNA probes.

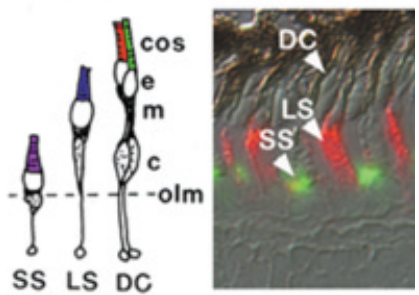

Four morphological/spectral types of cones in zebrafish.

Fig. 1. Spectral subtypes of photoreceptors in zebrafish. Radial, histological section of adult zebrafish retina, with the retinal pigmented epithelium and choroid at the top. Rod nuclei (r) in the outer nuclear layer, are connected by thin myoid processes to ellipsoids (arrowheads) and rod outer segments (ros). The four morphological/spectral cone subtypes are shown in the cartoon, with the cone outer segments (cos) color-coded to indicate the spectral peak of the opsin protein expressed in short single (SS), long single (LS) and double cones (DC). Other abbreviations: ellipsoid, e; myoid, m; cone nucleus, c; outer limiting membrane (olm) of the retina. The insert shows double in situ hybridization with two different opsin RNA probes and fluorescent detection. Methods: RNA probes are tagged with digoxigenin (DIG) or fluorescein (FL), respectively, and are detected with anti-DIG and anti-FL antibodies conjugated to horseradish peroxidase (HRP) or alkaline phosphatase (AP), respectively, and visualized with enzymatic substrates that produce contrasting fluorescent precipitates (Barthel and Raymond, 2000; Jowett, 2001). The Fast Red AP substrate is bright red in visible light, and it also fluoresces red with a rhodamine filter set. The TSA Biotin System uses HRP to catalyze the deposition of biotin-labeled tyramide, which is recognized by a streptavidin-fluorophore conjugate, such as fluorescein isothiocyanate (FITC). We performed control experiments to verify that the different detection methods have comparable sensitivity.

dimensional, mosaic pattern in the plane of the outer limiting membrane (Fig. 2). Viewed en face (in a retinal flat mount or in tangential sections of retina), the cones are precisely aligned in parallel rows of red and green double cone pairs that alternate with rows of alternating blue and UV single cones (Branchek and BreMiller, 1984; Raymond, 1995). Along each row of double cones, the orientation of the red/ green pairs alternately reverses. Adjoining rows of single or double cones are out-of-phase, shifted by one half cycle. Another striking geometric feature of the cone mosaic pattern is its internal, reiterative, mirror image symmetry: in the direction orthogonal to the rows of single and double cones, cones are arranged in an invariant sequence such that UV cones are always flanked by green cones, and blue cones are always flanked by red cones. Although the precise function of this highly ordered array of spectrally-tuned detectors is not understood, abundant electrophysiological and behavioral evidence demonstrates that teleost fish have highly developed mechanisms for color vision (Alpern, 1968; Wheeler, 1982; Neumeyer et al., 2002; Saszik et al., 2002).

\section{Retinal neurons, including cone photoreceptors, differentiate in a spatially organized and temporally coordinated pattern}

The organized array of cone photoreceptors in the zebrafish retina is assembled progressively by a spatiotemporally coordinated mechanism. The first retinal cells to differentiate, including photoreceptors, are always found in a distinct patch located in a topographically invariant position in the ventral retina at the junction of neural retina and optic stalk (Easter and Malicki, 2002). Subsequently, a wave of differentiation sweeps across the retinal primordium along a front resembling the hand of a clock moving from ventral to nasal to dorsal to temporal. This pattern of differentiation has been called a 'fan gradient', as it resembles the opening of a fan (Easter and Malicki, 2002). Differentiation also proceeds in an orderly sequence in the orthogonal dimension of the retinal primordium (i.e., across the retinal layers) - retinal ganglion cells in the innermost layer are born and differentiate first, followed by cells in the middle and outer layers, with photoreceptors differentiating last (Schmitt and Dowling, 1996; Hu and Easter, 1999; Schmitt and Dowling, 1999; Easter and Malicki, 2002). The general features of retinal differentiation in zebrafish are conserved in other vertebrates, i.e., inside-out and central-to-peripheral gradients of maturation(Easter, 2000). However, contrary to models of retinal neurogenesis based on mammalian and avian retinas, in which cells in the various retinal layers are produced sequentially, but simultaneously, in overlapping gradients (Adler, 2000; Livesey and Cepko, 2001) in the embryonic zebrafish retina, three sequential traveling waves of terminal mitoses (following the fan gradient) generate cells for each layer (Hu and Easter, 1999; Easter and Malicki, 2002).

The initiation and progression of retinal differentiation in zebrafish embryos is regulated, at least in part, by secreted Hedgehog $(\mathrm{Hh})$ signals that originate first from the optic stalk (Masai etal., 2000), then the retinal ganglion cells (Neumann and Nuesslein-Volhard, 2000), and finally the retinal pigmented epithelium (Stenkamp et al., 2000). However, the signaling mechanisms and molecular factors that create the cell-specific, laminar organization in the retina and that regulate retinal (and photoreceptor) cell fate choice are poorly understood.

Previous work from this laboratory (Raymond et al., 1995) and others (Branchek and BreMiller, 1984; Schmitt and Dowling,

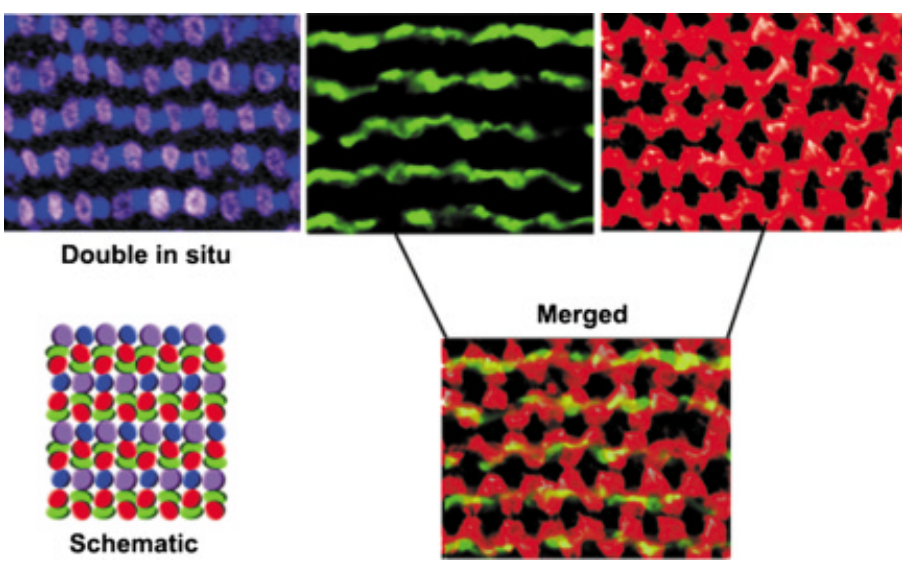

Fig. 2. Cone mosaic pattern in zebrafish. En face views of isolated, flattened, adult zebrafish retinas, processed for in situ hybridization with cone opsin RNA probes (fluorescent signals are pseudo-colored to correspond to the spectral subtype). At lower left is a cartoon schematic of the cone mosaic pattern. 
1996) established that the first rod and cone photoreceptors in zebrafish embryos differentiate (as reflected by opsin expression) at about 2 days after fertilization, in a small, discrete patch in ventral retina (Fig. $3 \mathrm{~A}, \mathrm{~B}$ ), which gradually expands, spreading across the retina along the fan gradient (Fig. $3 \mathrm{C}$ ). With the exception of the initial cohort of photoreceptors in the ventral patch, where rods and cones are produced simultaneously, the remainder of the presumptive photoreceptors generated by the third traveling wave of terminal mitoses in the outer nuclear layer differentiate as cones, with opsin expression following the fan gradient established earlier by the inner layers (Raymond et al., 1995). Significantly, the different spectral subtypes of cone photoreceptors are recruited, i.e., select a specific spectral fate, sequentially: red cone opsin is expressed first, followed shortly by green and later ultraviolet and blue opsins (Stenkamp et al., 1997).

With the possible exception of the precocious rod photoreceptors in the ventral patch, rod photoreceptors in zebrafish and other teleost fish are generated in a separate lineage that arises from

TABLE 1

\section{PHYLOGENY OF VISUAL PIGMENT GENES}

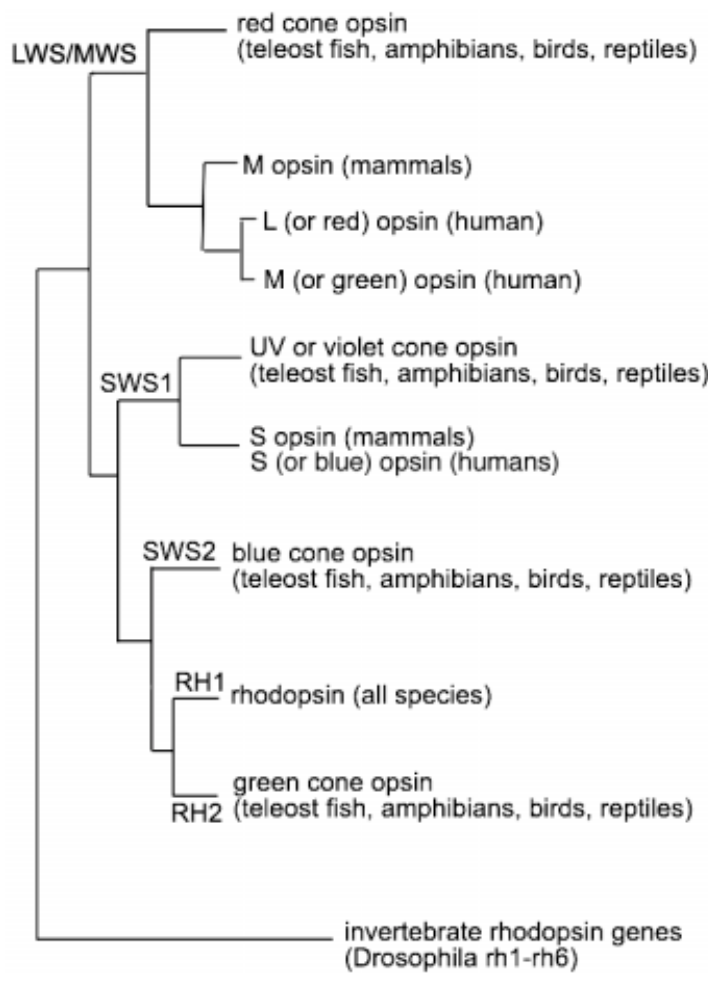

This dendrogram represents the evolutionary relationships of the visual pigment genes in vertebrates and invertebrates (adapted from (Pichaud et al., 1999; Yokoyama, 2000; Ebrey and Koutalos, 2001)). The major subgroups of cone opsin genes in vertebrates include LWS/MWS

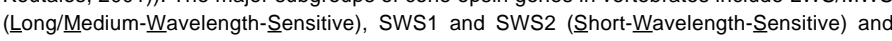
RH2 (Rhodopsin-like). In humans, the ancestral LWS/MWS gene on the X-chromosome underwent tandem duplication events with subsequent divergence to produce visual pigments with different spectral absorption maxima (Merbs and Nathans, 1992; Neitz and Neitz, 1995). The visual pigment in rod photoreceptors is Rhodopsin, or RH1. The medium-wavelength-sensitive (green) opsin of nonmammalian vertebrates (RH2) is closely related to rhodopsin, and the $\mathrm{RH}$ clade is the most highly diverged from the ancestral vertebrate pigment gene. The invertebrate visual pigments are represented by rhodopsins rh1 through rh6 in Drosophila. residual clusters of proliferating progenitors sequestered in association with Müller glia in the inner nuclear layer. These rapidly dividing progenitors migrate into the outer nuclear layer, where they undergo a few additional mitotic divisions as rod precursors before differentiating (Raymond, 1985b; Hoke and Fernald, 1998; Julian et al., 1998; Otteson and Hitchcock, 2003). As a consequence, the progression of rod opsin expression does not follow the fan gradient, but instead differentiating rods accumulate in a disorderly pattern across the embryonic retina (Raymond et al., 1995; Schmitt and Dowling, 1996). Rods do not to play a role in organizing the cone mosaic (Wan and Stenkamp, 2000), and they are not considered further in this discussion.

\section{The regular spacing of the cone mosaic array is established when the earliest photoreceptors differentiate}

At the onset of opsin expression, the cone spectral subtypes are already positioned in an organized array (Fig. 3 A,B). To quantify the spacing and regularity of the differentiating cones in the embryonic zebrafish retina, digital images of whole eyes processed for cone opsin expression visualized with fluorescent detection were captured with a laser scanning confocal microscope and analyzed with NIH Image software (Scion Image, Frederick, MD). The Scion Image program identifies the $x$ and $y$ coordinate values of the geometric center of each cone profile inside the area selected for analysis (box in Fig. 4), and these data were then imported into a custom software program (Cameron and Carney, 2000) used to calculate nearest neighbor distances in $\mu \mathrm{m}$ and other computational indicators of pattern regularity.

The nearest neighbor distance (NND) values plotted in Fig. 5 represent the means \pm 1 S.D. ( $n=32$ to 85 cones per eye, 2 or 3 eyes per bar, 21 eyes total). The frequency histograms of the NND values were computed and tested for deviation from a Gaussian distribution with the Kolmogorov-Smirnov method, and all distributions represented by the data plotted in Fig. 5 passed the normality test. Statistical analysis with ANOVA, and Tukey's Multiple Comparison Tests, indicated that for embryonic cones, $N N D_{\text {red }}<N N D_{\text {green }}<N N D_{\text {blue }}$, and $N N D_{U V}<N N_{\text {blue }}(p<0.001$ for all pairwise comparisons), but $\mathrm{NND}_{\mathrm{UV}}$ is not significantly different from $N N D_{\text {red }}$ or $N N D_{\text {green }}$ For the adult cones, $N_{N D_{\text {red }}<N N D_{\text {green }}}$ $<N N D_{\text {blue }}<N N D_{U V}(\mathrm{p}<0.001$ for all pairwise comparisons). The increased values of NND in the adult eye (Fig. 5) are due to both the increased size of individual cones with continued growth of the eye (Branchek and BreMiller, 1984; Raymond, 1985a) and the ongoing insertion of rod photoreceptors into the interstices of the cone mosaic through continued mitotic activity of rod precursors across the retina (Raymond, 1985b).

These data indicate that the cones of a given subtype are regularly spaced at the onset of opsin expression, which indicates they have selected a specific spectral fate. The mosaic array does not scale linearly with growth of the eye, however, since NND UV shows a larger change relative to the other cone types: UV cones are as closely spaced as red and green cones in the embryonic mosaic, and blue cones are the most widely spaced, but in the adult retina, UV cones are further apart from each other than all cone types, including blue cones. How these adjustments to the mosaic pattern are accomplished, and what the significance of these changes might be, is not yet understood. 

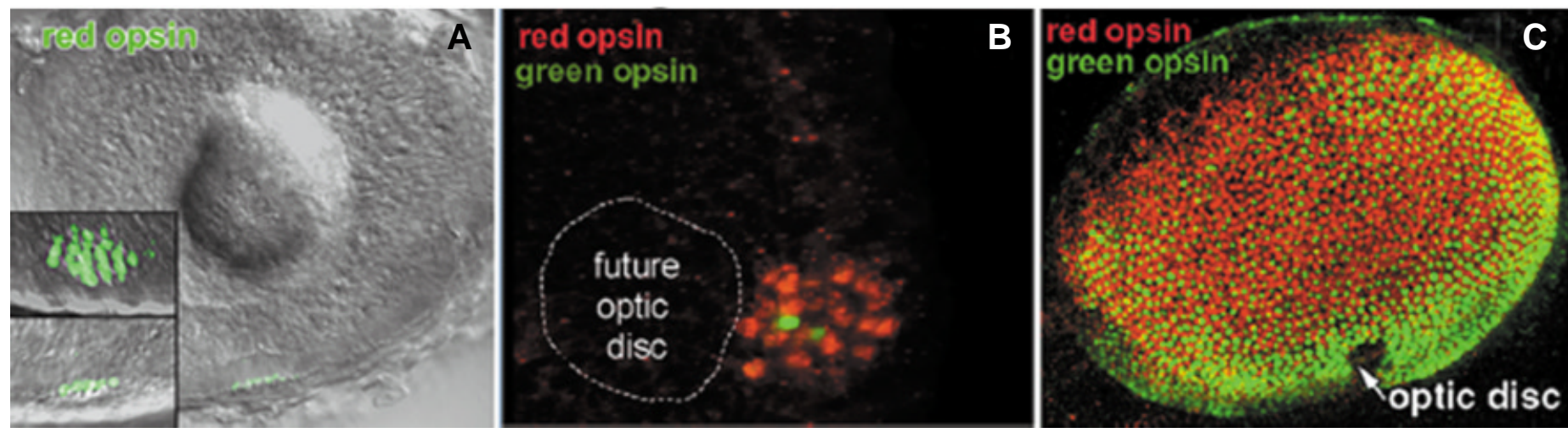

Fig. 3. Development of the cone mosaic pattern. Laser scanning confocal images (3D projections) from whole eyes of zebrafish embryos, processed for in situ hybridization with red and green opsin RNA probes to visualize individual cone photoreceptors. After processing, whole eyes are isolated from the embryonic heads and visualized using a Zeiss 510 laser scanning confocal microscope, by collecting a set of optical sections through the entire thickness of the eye $(\sim 100 \mu \mathrm{m})$. Computer reconstructions of three-dimensional and projection images were then generated from various angles of view. (A) The earliest photoreceptors appear at 2 days postfertilization (dpf) in the outer nuclear layer of the ventral-nasal retina adjacent to the optic stalk, and the first cone opsin is red (TSA method, FITC green fluorophore). The lens is visible in the center, and the inset shows the individual red cones at higher magnification, in orthogonal views. Note the regularly spaced rows of red cones in the rotated (planar) view. (B) Double in situ hybridization with red opsin (Fast Red) and green opsin (TSA-FITC) probes, showing (at high magnification) the ventral patch of initial cones, adjacent to the future optic disc. (C) By $\sim 3 d p f$, the front of the wave of differentiating photoreceptors has nearly reached the dorsal-temporal edge of the retina at the upper left corner, with red cones at the leading edge, trailed by green cones.

The most commonly used measure of pattern regularity in a two-dimensional array is an index called the 'conformity ratio' (CR), which is the ratio of the mean NND to the standard deviation (Cook, 1996). Jeremy Cook's 'Ready-reckoner' chart (Cook, 1996) provides empirically determined critical values of $\mathrm{CR}$ that define regular spacing. Values of $C R$ that fall above the critical value imply significant non-randomness, in the direction of regularity (as opposed to clumping) at the specified criterion level. The CRs for all cone arrays in both embryonic and adult samples exceeded the critical values at the criterion level of $p<0.0001$, indicating that both the adult and the initial cone mosaic array in the embryonic retina are highly regular, as inspection of the images suggests (Fig. 4).

Taken together, these data suggest that presumptive cone photoreceptors in zebrafish chose a unique cell fate with respect to cone spectral subtype, and that the choice of fate is dependent on a cell's relative position in the two-dimensional array of cone photoreceptors. The expression of a specific cone opsin gene is the only marker of spectral subtype currently available, aside from morphological differences (Fig. 1) that only develop with further maturation of the cone photoreceptors. However, the expression of opsin and other proteins of the transduction cascade are a relatively late event in the differentiation of photoreceptors in fish (Stenkamp et al., 1996) as in other vertebrates (Hauswirth et al., 1992; Bumsted et al., 1997; Sears et al., 2000), so it is possible that commitment to a specific spectral cell subtype occurs at an even earlier stage. The molecular mechanisms that control cell-fate choice among cone spectral subtypes in the zebrafish retina and the source of the patterning information are unknown. Finally, it is worth noting that we have never seen evidence of co-expression of multiple opsins in one cell, as has been reported in salamanders (Ma et al., 2001) and some mammals (Rohlich et al., 1994; Applebury et al., 2000; Lukats et al., 2002), although the relatively low sensitivity of the in situhybridization technique would likely not have allowed us to detect very low levels of expression in the developing zebrafish cones.

\section{Theoretical and experimental models which explain formation of other retinal mosaics cannot generate the cone mosaic pattern}

The fundamental cytoarchitecture of neuronal circuitry in the brain is built on reiterative, modular units, which in the retina takes the form of radial units that mediate serial visual processing across retinal laminae (photoreceptor to bipolar cell to ganglion cell), and intralaminar parallel processing circuits mediated by lateral connectivity (horizontal and amacrine cells) (Cook and Chalupa, 2000; Masland and Raviola, 2000; Galli-Resta, 2001). Since the $19^{\text {th }}$ century, it has been known that retinal neurons of the same type are distributed across the retinal surface in non-random, regularly spaced arrays, called mosaics. This periodicity in spacing

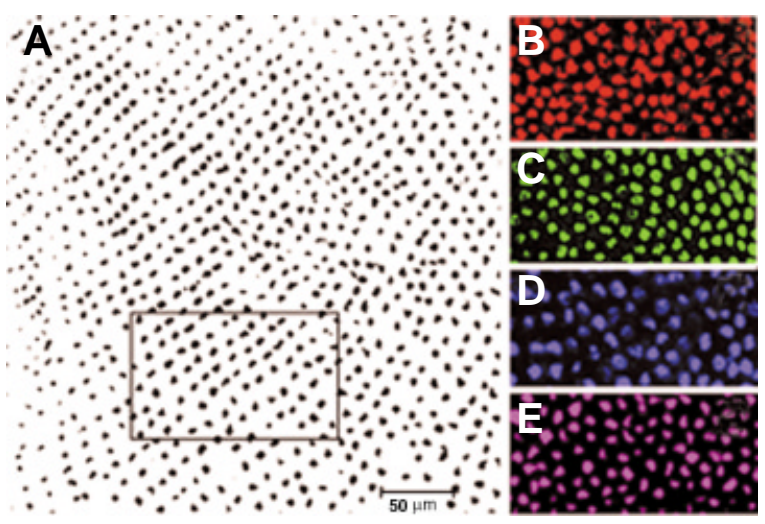

Fig. 4. Computational analysis of cone mosaic patterns. (A) Scion Image data file of an adult retinal whole mount processed for in situ hybridization (blue opsin), in which the area selected for analysis is boxed. (B-E) Confocal images of embryonic retinas at $\sim 3 d$ pf processed with red, green, blue or UV opsin probe (pseudo-colored), respectively. 
of homotypic neurons can arise early in development (McCabe et al., 1999), but is subject to refinement by lateral (tangential) migration of cells whose desired position is subject to a 'minimal exclusion rule', in which no two cells of the same type are ever closer than a minimum distance (Wässle and Riemann, 1978; Cook and Chalupa, 2000; Galli-Resta, 2001). Modeling studies show that short-range, dynamic, physical interactions that minimize overlap between homotypic neurons are sufficient to produce a regular mosaic array that uniformly 'tiles' the retina (Galli-Resta et al., 2002; Reese and Galli-Resta, 2002). Misplaced neurons can also be eliminated by selective cell death (Cook and Chalupa, 2000). A local exclusion rule based on interactions among homotypic neurons predicts that the mosaic arrays of different classes of retinal neurons should be uncorrelated, and this is indeed the case, including classes of neurons known to be synaptically coupled (Rockhill et al., 2000). However, the cone photoreceptor mosaic in teleost fish retinas is a clear exception, in that each spectral subtype is precisely positioned in relationship to cones of a different subtype (Fig. 2). Therefore, the simple minimal exclusion rule cannot account for the patterning of the cone photoreceptor mosaic in teleost fish.

Theoretical mathematical models have been developed that reproduce the organization of the cone mosaic in zebrafish, and they all invoke specific cell-cell interactions among spectral cone subtypes. One of the earliest modeling attempts relied on a starting condition consisting of a two-dimensional, square lattice of undifferentiated cells, with a stochastic cell-differentiation rule to create the initial (random) 'prepattern' (Tohya et al., 1999). The prepattern is subsequently refined by transitions in cone type (i.e., changes in spectral identity) and cell orientation that are stabilized according to the strength of 'cell affinities' with neighboring cones. While this 'fate transition' model faithfully creates the cone mosaic array, the assumption that phenotypic transitions (i.e., changes in spectral identity) occur does not fit the observations described above.

A more recently published theoretical model (Mochizuki, 2002) also starts from an initially random, two-dimensional array of three cone subtypes but in this case the spectral subtypes are constrained to the correct ratio (twice as many red/green double cones as blue or UV). Cell rearrangements (exchanges of position on the lattice) and rotations occur randomly, and transitions are more rapid if total cell-cell adhesion between neighbors is increased. Interestingly, the number of iterations required to reach the correct (stable) pattern is reduced when the process is allowed to proceed in a linear wave across the array, which in fact mimics the biological situation (Fig. 3C). The parameters of the 'cell rearrangement' model that reproduced the correct mosaic pattern required that the adhesive strengths between blue-UV, blue-red, UV-green and redgreen be larger than the remaining six contact pairs, reflecting the nearest neighbor relationship in the array (Fig. 2).

Observations of the developing cone mosaic array in zebrafish embryos show that when spectral cone subtypes can first be recognized by expression of opsin, they are not randomly positioned but already in a regular array (Fig. 5). Thus, lateral migration/cell sorting driven by differential adhesive interactions are not likely to generate the mosaic pattern, unless cone spectral fate is determined prior to opsin expression. As noted above, no other specific markers of differentiation that distinguish among the cone spectral subtypes have yet been described, and until such markers are identified, this possibility cannot be tested.

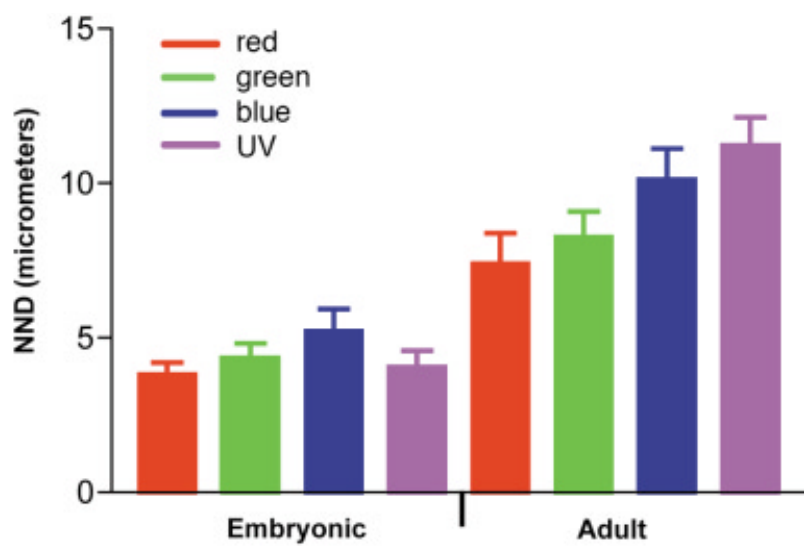

Fig. 5. Spacing of cone subtypes. Mean nearest neighbor distances (NND) \pm S.D. between cones of the same subtype in embryonic and adult retinas. The bars are color-coded according to opsin spectral subtype: red, green, blue and UV.

An alternative mechanism for patterning the cone mosaic is that specific cell-cell signaling interactions among the differentiating cone photoreceptors dictate the choice of cone cell fate. In this case, the relative strengths of adhesive interactions predicted by the mathematical model described above may suggest which specific cell-cell signaling interactions might be most important in fate determination and patterning of zebrafish cone photoreceptors. A model describing this potential mechanism is presented next.

\section{Photoreceptor cell fate determination in the compound eye of Drosophila may provide clues to molecular mechanisms that could explain the teleost cone mosaic pattern}

Some features of organization and development of cone photoreceptor patterning in the zebrafish retina resemble that of the compound eye of the fruit fly, Drosophila melanogaster (Raymond, 1995; Pichaud et al., 2001). The eye of the adult fly is an exquisitely organized array composed of $\sim 800$ individual ommatidia, or 'facet eyes', each containing 8 uniquely identified photoreceptor cells assembled into highly stereotyped, geometrically precise, reiterative units with internal, mirror-image symmetry (Ready etal., 1976; Tomlinson and Ready, 1987; Rubin, 1989; Banerjee and Zipursky, 1990). The ommatidia are assembled with a crystalline precision from an undifferentiated monolayer epithelium, and the assembly proceeds along a linear, moving front called the 'morphogenetic furrow' (Fig. 6A). The furrow sweeps across the eye primordium patterning the retina from posterior to anterior, and its movement is driven by the coordinated expression of positive and negative, short- and long-range factors that regulate the orderly progression of differentiation and the sequential assembly of the ommatidial units (Kumar and Moses, 1997; Brennan and Moses, 2000; Frankfort and Mardon, 2002). Remarkably, one of these factors is Hedgehog, which also has been implicated in driving the progression of the wave of differentiation in the vertebrate retina (discussed above).

The R8 photoreceptor is the 'founder', i.e., the first cell specified in the ommatidial unit, and it is required for recruitment of the seven 
other photoreceptors and the accessory cells (Ready et al., 1976; Tomlinson and Ready, 1987; Rubin, 1989; Banerjee and Zipursky, 1990) (Fig. 6A). The specification and precise spacing of the R8 photoreceptors sets up the template for the ommatidial array, and commitment of the $\mathrm{R} 8$ photoreceptors requires the sequential positive (proneural enhancement) and negative (lateral inhibition) activities of the Notch signaling pathway (Brennan and Moses, 2000; Frankfort and Mardon, 2002). R8 subsequently recruits the other photoreceptors to the nascent ommatidial cluster pairwise in a specified order (R2/R5, R3/R4, R1/R6) by a process that involves reiterative signaling through the epidermal growth factor receptor (EgfR) (Fig. 6A). Although the R1 to R6 outer photoreceptors in the fly eye all express the same visual pigment gene (rh1, Table 1), they have distinct identifies and can be distinguished from one another by their position in the ommatidial cluster and by the expression of specific transcription factors (Brennan and Moses, 2000; Frankfort and Mardon, 2002). The final step in assembly of each 8-photoreceptor unit is mediated through another tyrosine kinase receptor, Sevenless, and its membrane-bound ligand (Brideof-Sevenless, Boss), which is uniquely expressed on R8. Through this direct, cell-cell interaction R8 specifies its functional and anatomical partner, the last photoreceptor generated, R7 (Fig. 6A).
The R8 and R7 pair of inner photoreceptors express visual pigment genes that differ both from each other and from the R1-R6 photoreceptors, and the choice of which rhgenes are expressed by the $R 7 / R 8$ pair in a given ommatidium depends on a direct cell-cell interaction between them (Cook and Desplan, 2001).

In Drosophila, the successive recruitment of photoreceptors to the ommatidial units and the establishment of their identities begins just after each generation of precursor cells withdraws from the mitotic cycle and while they are aligned in a linear array at the posterior edge of the morphogenetic furrow (Fig. 6A). Similarly, the cone mosaic array in the fish retina is constructed by step-wise accretion of linear, modular units (Raymond, 1995). The rows of double and single cones shown in Fig. 2 are aligned orthogonal to the peripheral retinal margin (Lyall, 1957), and radiate outward like spokes on a wheel from the optic disc, with new spokes arising de novo as the circumference of the retinal sphere increases (Nishiwaki et al., 1997). After the early waves of cell differentiation have established the embryonic retina, neurogenesis continues in the circumferential germinal zone at the peripheral edge (also called the ciliary margin (Perron etal., 1998)). The continued growth at the margin recapitulates the embryonic sequence of retinal neurogenesis (Müller, 1952; Raymond, 1995), and each new

\section{A

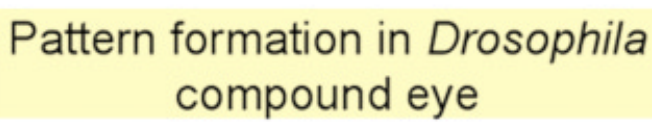

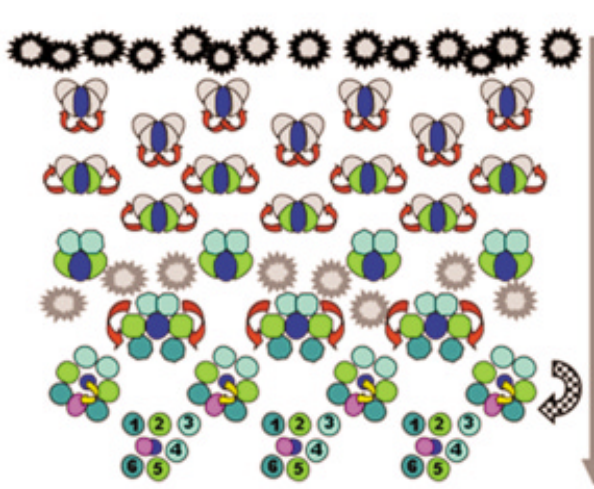

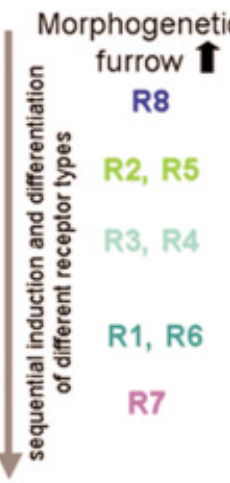

\section{B

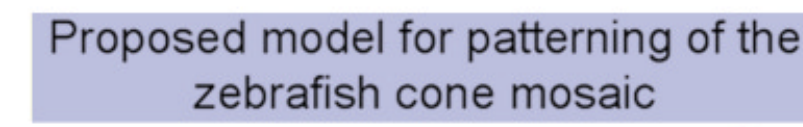

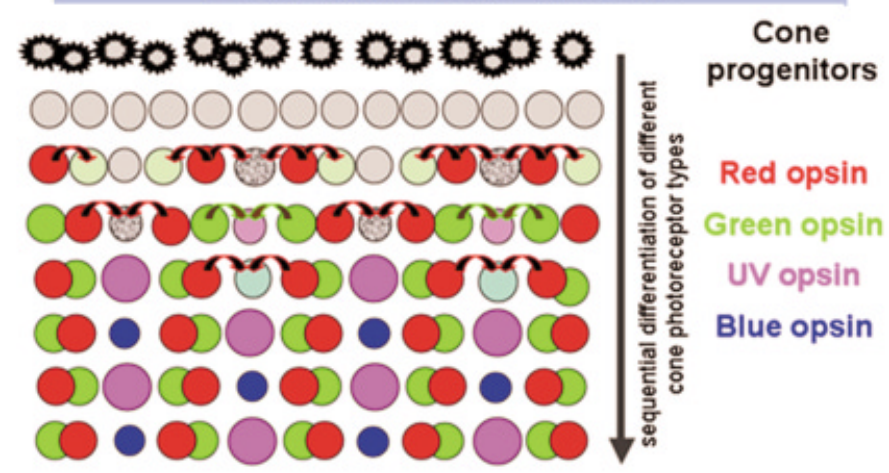

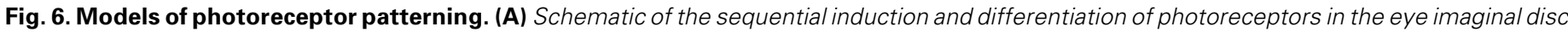

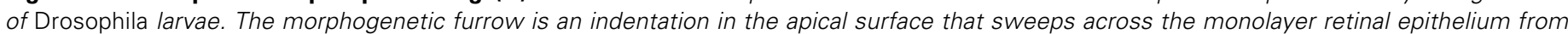

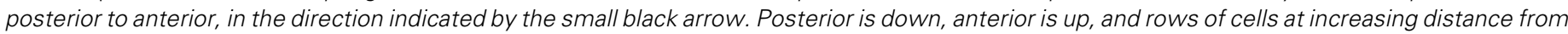

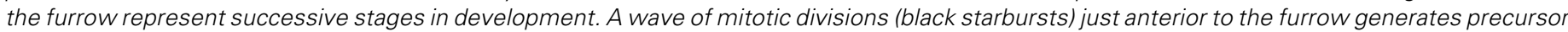

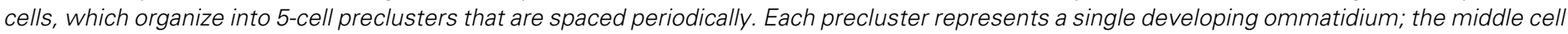

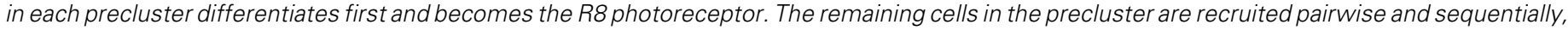

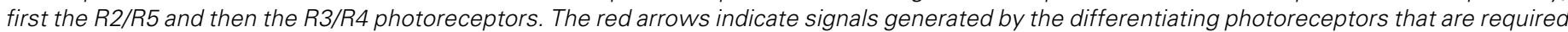

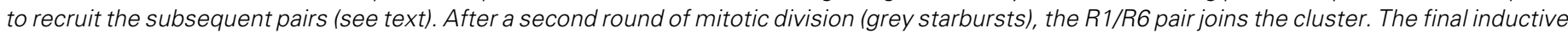

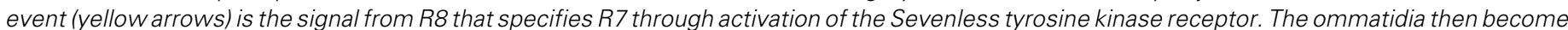

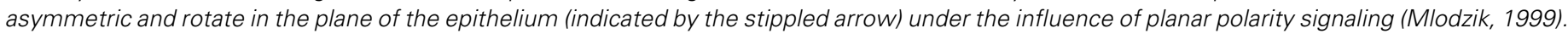

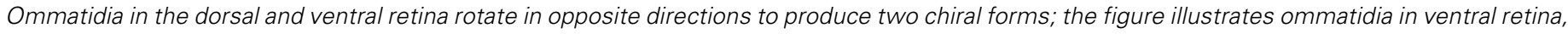

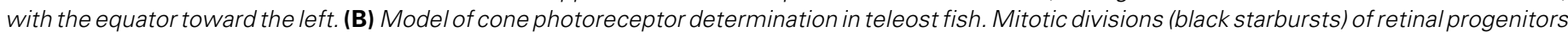

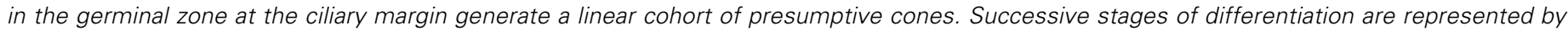

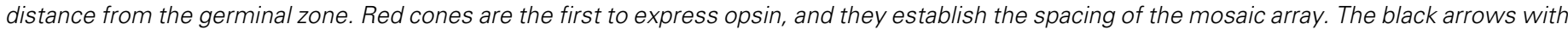

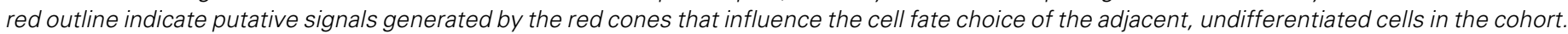

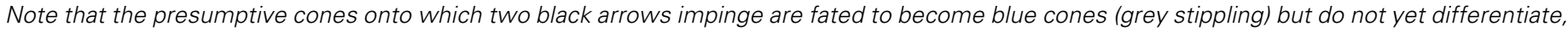

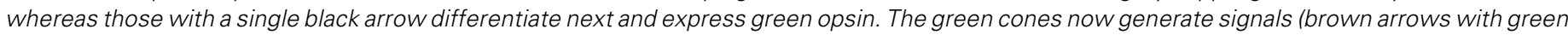

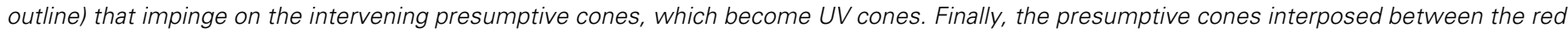
cones express blue opsin. 
cohort of presumptive cones is born along a circular, two-dimensional front (Fig. 6B) quite analogous to the morphogenetic furrow (Fig. $6 \mathrm{~A}$ ). In both the embryonic retina (Fig. 3) and during continued growth of the retina postembryonically by the addition of new retina generated from proliferating progenitors at the ciliary margin (Fig. $6 \mathrm{~B})$, cones differentiate sequentially along a moving front of differentiation according to their spectral subtype: first red cones, then green, then UV and blue (Raymond et al., 1995; Stenkamp et al., 1997). Thus, the construction of the mosaic array in the teleost retina is consistent with the hypothesis that lateral interactions (signals) from the 'founder' red cones might influence the cell fate of adjacent, uncommitted presumptive cones (Fig. 6B), similar to the fly eye in which signals emanating from differentiating photoreceptors, in conjunction with time-dependent intrinsic changes in the status of the progenitors, are responsible for organizing and determining the fate of photoreceptors (Fig. 6A).

The neural retina in adult fish can regenerate neurons, including cone photoreceptors (Raymond and Hitchcock, 2000; Wu et al., 2001; Otteson and Hitchcock, 2003). Although retinal neurons are replaced, including all spectral cone subtypes, the precise geometric organization of the cone mosaic array is not restored in the regenerated retina (Braisted et al., 1994; Cameron and Carney, 2000; Stenkamp and Cameron, 2002). The spatiotemporal sequence of proliferation and cell differentiation in the regenerating retina does not recapitulate the coordinated planar gradient of photoreceptor neurogenesis seen in the embryonic and postembryonic retina. This observation provides strong support for the hypothesis that the precise spatiotemporal coordination of the production and differentiation of cone progenitors along a moving curvilinear front as seen in normal growth and development (Figs. 3 and $6 \mathrm{~B}$ ) is critical to the processes that create the cone mosaic array.

In summary, a number of features of the ommatidial assembly process in the compound eye of Drosophila are strikingly similar to the formation of the cone mosaic array in zebrafish including: a focal site of initiation adjacent to the optic stalk; progression of a wave of differentiation across the undifferentiated epithelium that is dependent on Hedgehog signaling; establishment of the spacing of the mosaic array by the first subtype of photoreceptor to differentiate; and sequential, reiterative recruitment of the other photoreceptor subtypes.

The molecular mechanisms that pattern the cone mosaic array in teleost fish are unknown. The model illustrated in Fig. 6B suggests that cell-cell signals from differentiating cones of a given spectral subtype influence the fate of yet undifferentiated progenitors. Extrinsic signals might also originate from outside the planar sheet of cone progenitors, for example, from the adjoining inner retinal layers, which are already well differentiated at the onset of cone opsin expression. However, as noted above, spatial organization in the inner layers is limited to uncorrelated, homotypic mosaic arrays of neuronal subtypes, which do not contain the planar spatial information related to cone spectral subtype encoded in the cone mosaic. The power of forward genetic approaches developed in zebrafish provides the best opportunity to discover genes involved in the determination of cone cell fate and mosaic organization (van Eeden etal., 1999; Malicki, 2000). A mutagenesis screen currently underway in our laboratory has identified several mutations that specifically disrupt cone patterning without disrupting cell fate determination in other retinal layers (P.A. Raymond, et al., unpublished observations), suggesting that the molecular mechanisms responsible for determination of cone spectral identify likely reside within the photoreceptor layer, as predicted by the model in Fig. 6B.

\section{Discovering the molecular mechanisms that pattern the cone mosaic array in the zebrafish retina may contribute to understanding human visual function}

Some (but not all) features of the planar organization and differentiation of cone photoreceptors as described above for the teleost retina are also found in humans. For example, in primate and human retinas, the S-cones (Short-wavelength-sensitivecones, or blue cones) are organized into a regular mosaic array (Wikler et al., 1990; Wikler etal., 1997; Roorda and Williams, 1999; Kimble and Williams, 2000). In developing chick, monkey, and human retinas, the spectral subtypes of cone photoreceptors are recruited sequentially in a wave of retinal differentiation that starts centrally and spreads peripherally. Whereas the order of onset of cone opsin expression in chick retinas (Bruhn and Cepko, 1996; Cepko, 1996) is the same as in goldfish and zebrafish (Raymond et al., 1995; Schmitt and Dowling, 1996; Stenkamp et al., 1997), mammals differ in the relative order of differentiation of spectral cone subtypes: S-cone (Short-wavelength-sensitive) opsin mRNA and protein both appear significantly earlier in the fetal primate retina than L-cone and M-cone (Long- and Mediumwavelength-sensitive, respectively) opsin mRNA or protein (Bumsted et al., 1997; Xiao and Hendrickson, 2000). The mammalian S-cone opsin is in the SWS1 family of visual pigment genes, as is the teleost UV cone opsin, and the mammalian M-cone opsin gene is in the LWS/MWS family, which is in the same gene family as the red cone opsin of teleosts, amphibians, birds and reptiles (Table 1 ). During the evolution of mammals, the orthologs of the green (RH2) and blue (SWS2) cone opsin genes found in other vertebrates were lost (Yokoyama, 2000).

S-cone opsin expression also appears before M-cone opsin in the developing mouse retina (Szel et al., 1993), and it has been postulated that in developing mammalian retinas, successive waves of local inducing factors might first determine S-cones, and then later L/M cones (Xiao and Hendrickson, 2000). This hypothesis is supported by the observation that differentiating cones in developing mouse and primate retinas express both S-cone opsin and $\mathrm{L} / \mathrm{M}$-cone opsin in the transition zone, at the leading edge of the front of L/M-cone opsin as it moves into a region of pre-existing Scone opsin expression, suggesting that some developing cones may switch their spectral subtype (Rohlich et al., 1994; Xiao and Hendrickson, 2000). Co-expression of SWS1 (UV opsin/S-cone opsin) with other opsins has also been demonstrated in differentiated cone photoreceptors in other species, such as salamanders (Makino and Dodd, 1996) and other mammals (Szel et al., 2000) including mice (Applebury et al., 2000), but whether this reflects a specific cell fate choice or 'leakiness' in transcriptional regulation of opsin gene expression is unclear. Instability in the expression of specific opsin genes in differentiating photoreceptors has also been observed in the developing chick retina, but in that case, the red cone opsin (LWS/MWS family) is the initial or preferred choice (Adler et al., 2001). In contrast, in the zebrafish, the choice of a specific cone spectral subtype is a unique and apparently permanent determination event. 
In humans, as in teleost fish, there is clear anatomical, electrophysiological and behavioral evidence of unique spectral cone subtypes ( $\mathrm{S}$ and $\mathrm{L} / \mathrm{M}$ ) with distinct cytology and synaptic connectivity that mediate the distal mechanisms of color vision (Alpern, 1968; Wheeler, 1982; Ahnelt et al., 1990). Genetic evidence also supports the notion of unique cone subtypes in humans: an inherited retinal disorder called enhanced S-cone syndrome (ESCS) leads to overproduction of S-cones at the expense of other photoreceptor subtypes, and patients suffer visual loss and night blindness, with increased sensitivity to shortwavelength lights (Milam et al., 2002). Mutations in the gene encoding a transcription factor in the orphan nuclear receptor family, NR2E3 (also called photoreceptor-specific nuclear receptor, PNR), have recently been identified as causal for ESCS (Kobayashi et al., 1999; Haider et al., 2000). Nr2e3/PNR is unique in that its expression is highly restricted to the neural retina, where it localizes exclusively to the outer nuclear layer (Kobayashi et al., 1999), similar to the cone-rod homeobox transcription factor, Crx (Chen etal., 1997; Furukawa et al., 1997). A spontaneous mouse retinal degeneration mutation ( $r d 7$ ) results from a frame-shift deletion in Nr2e3, which like the human disease, leads to excess photoreceptors that express high levels of S-cone opsin, retinal folding and rosettes in the outer nuclear layer, especially the ventral retina, and late-onset photoreceptor degeneration (Haider etal., 2001). These data implicate $\mathrm{Nr2e} 3$ in the positive regulation of L/M-cone opsin, and suggest that in the absence of Nr2e3 function the 'default' state is expression of S-cone opsin.

Another transcription factor implicated in photoreceptor cell fate determination is the nuclear protein $\mathrm{Nrl}$ (neural retina leucine zipper), a member of the Maf subfamily of basic zipper (bZIP) transcription factors (Swaroop et al., 1992). Nrl regulates the expression of several rod-specific genes, including rhodopsin and cGMP phosphodiesterase $\beta$-subunit, in synergy with other transcription factors, such as Crx (Rehemtulla et al., 1996; Mitton et al., 2000). Nrl expression in mice is restricted to rod photoreceptors, and perhaps the pineal gland, and it is required for rod photoreceptor differentiation. Targeted deletion of $\mathrm{Nr} /$ in mice results in the loss of rod function and supernormal S-cone function, apparently resulting from the partial transformation of presumptive rod photoreceptors into S-cones (Mears etal., 2001). Missense mutations in the human NRL gene are associated with autosomal dominant retinitis pigmentosa (Bessant et al., 1999). Expression of $\mathrm{Nr2e} 3$ is absent in $\mathrm{Nr}^{-/-}$mice, suggesting that $\mathrm{Nrl}$ is upstream of $\mathrm{Nr} 2 \mathrm{e} 3$ in the transcriptional hierarchy, and supporting the idea that the function of $\mathrm{Nrl}$ may be to promote rod photoreceptor differentiation and inhibit S-cone differentiation by activation of Nr2e3.

In vitro studies have also implicated thyroid hormone in the determination and differentiation of cone photoreceptors in dissociated rat retinal cell cultures (Kelley et al., 1995). Recently it was shown that the thyroid hormone receptor $\beta 2(\operatorname{Tr} \beta 2)$ (a nuclear receptor/ligand-dependent transcription factor) is required for the development of M-cones ( $\mathrm{Ng}$ et al., 2001). The expression of the $\operatorname{Tr} \beta 2$ isoform is restricted to the outer nuclear layer of the retina, the pituitary gland and the inner ear in mice and chick, and levels of expression in the retina peak during late embryonic development, while cones are differentiating. Targeted deletion of the Thrb gene in mice results in premature expression of Scone opsin, selective loss of $\mathrm{M}$-cones and a concomitant increase in functional S-cones, as demonstrated by enhanced sensitivity to short-wavelengths in electroretinogram recordings $(\mathrm{Ng}$ et al., 2001). Unlike the $\mathrm{Nr}^{-1-}$ mice, rod function was normal in Thrb mice. Interestingly, in salmonids (e.g. rainbow trout), thyroxine also regulates the development of UV cones (Browman and Hawryshyn, 1994; Allison et al., 2003; Hawryshyn et al., 2003), which like mammalian S-cones express an SWS1 opsin gene.

In summary, these studies suggest that specific transcription factors as well as extrinsic signals are implicated in vertebrate photoreceptor cell fate choice, i.e., to be a cone or a rod and, if a cone, which spectral subtype. The exquisite regularity of the cone mosaic array in teleost fish and the proven utility of zebrafish genetics for discovering genes important in developmental processes suggest that analysis of pattern formation in the cone mosaic of zebrafish embryos will provide a powerful model for uncovering these mechanisms.

\section{Acknowledgements}

Supported by NIH R01 EY004318 and NIH P60 DK20572. We are grateful to David Cameron for assistance with the nearest-neighbor analysis and to Thomas Vihtelic and David Hyde for providing the zebrafish cone opsincDNAs. We also thank Claude Desplan for stimulating discussions and two anonymous reviewers for their insightful comments on an earlier draft of this paper.

\section{References}

ADLER, R. (2000). A model of retinal cell differentiation in the chick embryo. Prog Retin Eye Res 19: 529-557.

ADLER, R., TAMRES, A., BRADFORD, R. L.and BELECKY-ADAMS, T. L. (2001). Microenvironmental regulation of visual pigment expression in the chick retina. Dev Bio/236: 454-464.

AHLBERT, I.-B. (1968). The organization of the cone cells in the retinae of four teleosts with different feeding habits (Perca fluviatilis, Lucioperca lucioperca, Acerina cernua, and Coregonus albula). Arkiv Zool22: 445-481.

AHNELT, P., KERI, C.and KOLB, H. (1990). Identification of pedicles of putative blue-sensitive cones in the human retina. J Comp Neuro/293: 39-53.

AIELLO, L. M. (2003). Perspectives on diabetic retinopathy. Am JOphthalmo/136: 122-135.

ALLISON, W. T., DANN, S. G., HELVIK, J. V., BRADLEY, C., MOYER, H. D.and HAWRYSHYN, C. W. (2003). Ontogeny of ultraviolet-sensitive cones in the retina of rainbow trout (Oncorhynchus mykiss). J Comp Neuro/461: 294-306.

ALPERN, M. (1968). Distal mechanisms of vertebrate color vision. Annu Rev Physio/30: 279-318

AMBATI, J., AMBATI, B. K., YOO, S. H., IANCHULEV, S.and ADAMIS, A. P. (2003). Age-Related Macular Degeneration: Etiology, Pathogenesis, and Therapeutic Strategies." Survey of Ophthalmology 48: 257-293.

APPLEBURY, M. L., ANTOCH, M. P., BAXTER, L. C., CHUN, L. L., FALK, J. D., FARHANGFAR, F., KAGE, K., KRZYSTOLIK, M. G., LYASS, L. A. and ROBBINS, J. T. (2000). The murine cone photoreceptor: a single cone type expresses both $S$ and $M$ opsins with retinal spatial patterning. Neuron 27: 513-523.

BANERJEE, U.and ZIPURSKY, S. L. (1990). The role of cell-cell interaction in the development of the Drosophila visual system. Neuron 4: 177-187.

BARTHEL, L. K.and RAYMOND, P. A. (2000). In situ hybridization studies of retinal neurons. In Vertebrate Phototransduction and the Visual Cycle. K. Palczewsk [eds.], Orlando, FL, Academic Press. 316, Part B: 579-590.

BESSANT, D. A., PAYNE, A. M., MITTON, K. P., WANG, Q. L., SWAIN, P. K., PLANT, C., BIRD, A. C., ZACK, D. J., SWAROOP, A. and BHATTACHARYA, S. $S$. (1999). A mutation in NRL is associated with autosomal dominant retinitis pigmentosa. Nat Genet 21: 355-356.

BRAISTED, J. E., ESSMAN, T. F.and RAYMOND, P. A. (1994). Selective regeneration of photoreceptors in goldfish retina. Development 120: 24092419. 
BRANCHEK, T.and BREMILLER, R. (1984). The development of photoreceptors in the zebrafish, Brachydanio rerio. I. Structure. J Comp Neuro/224: 107-115.

BRENNAN, C. A.and MOSES, K. (2000). Determination of Drosophila photoreceptors: timing is everything. Cell Mol Life Sci57: 195-214.

BROWMAN, H. I. and HAWRYSHYN, C. W. (1994). The developmental trajectory of ultraviolet photosensitivity in rainbow trout is altered by thyroxine. Vision Res 34: 1397-1406

BRUHN, S. L. and CEPKO, C. L. (1996). Development of the pattern of photoreceptors in the chick retina. JNeurosci 16: 1430-1439.

BUMSTED, K., JASONI, C., SZEL, A. and HENDRICKSON, A. (1997). Spatial and temporal expression of cone opsins during monkey retinal development. $J$ Comp Neuro/378: 117-134.

CAMERON, D. A. and CARNEY, L. H. (2000). Cell mosaic patterns in the native and regenerated inner retina of zebrafish: implications for retinal assembly. J Comp Neuro/416: 356-367.

CEPKO, C. L. (1996). The patterning and onset of opsin expression in vertebrate retinae. Curr Opin Neurobio/6: 542-546.

CEPKO, C. L. (1999). The roles of intrinsic and extrinsic cues and bHLH genes in the determination of retinal cell fates. Current Opinion in Neurobiology 9: 37-46.

CHEN, S. M., WANG, Q. L., NIE, Z. Q., SUN, H., LENNON, G., COPELAND, N. G. GILBERT, D. J., JENKINS, N. A. and ZACK, D. J. (1997). Crx, a novel Otx-like paired-homeodomain protein, binds to and transactivates photoreceptor cellspecific genes. Neuron 19: 1017-1030.

CHINEN, A., HAMAOKA, T., YAMADA, Y. and KAWAMURA, S. (2003). Gene duplication and spectral diversification of cone visual pigments of zebrafish. Genetics 163: 663-675.

COHEN, A. I. (1972). Rods and cones. In Handbook of Sensory Physiology. M. G. F. Fourtes [eds.], New York, Springer-Verlag. VII/2: 63-110.

COOK, J. E. (1996). Spatial properties of retinal mosaics: an empirical evaluation of some existing measures. Vis Neurosci13: 15-30.

COOK, J. E. and CHALUPA, L. M. (2000). Retinal mosaics: new insights into an old concept. Trends Neurosci23: 26-34.

COOK, T.and DESPLAN, C. (2001). Photoreceptor subtype specification: from flies to humans. Semin Cell Dev Biol12: 509-518.

DOWLING, J. E. (1987). The Retina. Boston, Harvard University Press.

EASTER, S. S., JR. (2000). Let there be sight. Neuron 27: 193-195.

EASTER, S. S., JR. and MALICKI, J. J. (2002). The zebrafish eye: developmental and genetic analysis. Results Prob/ Cell Differ 40: 346-370.

EBREY, T. and KOUTALOS, Y. (2001). Vertebrate photoreceptors. Prog Retin Eye Res 20: 49-94.

ENGSTRÖM, K. (1960). Cone types and cone arrangement in the retina of some cyprinids. Acta Zoo/41: 277-295.

ENGSTRÖM, K. (1963). Cone types and cone arrangements in teleost retinae. Acta Zool44: 179-243.

FRANKFORT, B. J. and MARDON, G. (2002). R8 development in the Drosophila eye: a paradigm for neural selection and differentiation. Development 129: 1295-1306.

FURUKAWA, T., MORROW, E. M. and CEPKO, C. L. (1997). Crx, a novel otx-like homeobox gene, shows photoreceptor-specific expression and regulates photoreceptor differentiation. Cel/91: 531-541.

GALLI-RESTA, L. (2001). Assembling the vertebrate retina: global patterning from short-range cellular interactions. Neuroreport 12: A103-106.

GALLI-RESTA, L., NOVELLI, E. and VIEGI, A. (2002). Dynamic microtubuledependent interactions position homotypic neurones in regular monolayered arrays during retinal development. Development 129: 3803-3814.

HAIDER, N. B., JACOBSON, S. G., CIDECIYAN, A. V., SWIDERSKI, R., STREB, L. M., SEARBY, C., BECK, G., HOCKEY, R., HANNA, D. B., GORMAN, S., DUHL, D., CARMI, R., BENNETT, J., WELEBER, R. G., FISHMAN, G. A., WRIGHT, A. F., STONE, E. M. and SHEFFIELD, V. C. (2000). Mutation of a nuclear receptor gene, NR2E3, causes enhanced $S$ cone syndrome, a disorder of retinal cell fate. Nat Genet 24: 127-131.

HAIDER, N. B., NAGGERT, J. K. and NISHINA, P. M. (2001). Excess cone cell proliferation due to lack of a functional NR2E3 causes retinal dysplasia and degeneration in rd7/rd7 mice. Hum Mol Genet 10: 1619-1626.
HAUSWIRTH, W. W., LANGERIJT, A. V., TIMMERS, A. M., ADAMUS, G. and ULSHAFER, R. J. (1992). Early expression and localization of rhodopsin and interphotoreceptor retinoid-binding protein (IRBP) in the developing fetal bovine retina. Exp Eye Res 54: 661-670.

HAWRYSHYN, C. W., MARTENS, G., ALLISON, W. T. and ANHOLT, B. R. (2003). Regeneration of ultraviolet-sensitive cones in the retinal cone mosaic of thyroxinchallenged post-juvenile rainbow trout (Oncorhynchus mykiss). J Exp Bio/206: 2665-2673.

HOKE, K. L. and FERNALD, R. D. (1998). Cell death precedes rod neurogenesis in embryonic teleost retinal development. Dev Brain Res 111: 143-146.

HU, M.and EASTER, S. S. (1999). Retinal neurogenesis: the formation of the initial central patch of postmitotic cells. Dev Bio/207: 309-321.

JOWETT, T. (2001). Double in situ hybridization techniques in zebrafish. Methods 23: $345-358$

JULIAN, D., ENNIS, K. and KORENBROT, J. I. (1998). Birth and fate of proliferative cells in the inner nuclear layer of the mature fish retina. JComp Neuro/394: 271 282.

KELLEY, M. W., TURNER, J. K. and REH, T. A. (1995). Ligands of steroid/thyroid receptors induce cone photoreceptors in vertebrate retina. Development 121 : 3777-3785.

KIMBLE, T. D. and WILLIAMS, R. W. (2000). Structure of the cone photoreceptor mosaic in the retinal periphery of adult humans: analysis as a function of age, sex, and hemifield. Anat Embryol (Berl) 201: 305-316.

KOBAYASHI, M., TAKEZAWA, S., HARA, K., YU, R. T., UMESONO, Y., AGATA, K., TANIWAKI, M., YASUDA, K. and UMESONO, K. (1999). Identification of a photoreceptor cell-specific nuclear receptor. Proc Nat/ Acad Sci USA 96: 48144819.

KUMAR, J. and MOSES, K. (1997). Transcription factors in eye development: a gorgeous mosaic? Genes Dev 11: 2023-2028.

LARISON, K. D. and BREMILLER, R. (1990). Early onset of phenotype and cell patterning in the embryonic zebrafish retina. Development 109: 567-576.

LEVINE, E. M., FUHRMANN, S. and REH, T. A. (2000). Soluble factors and the development of rod photoreceptors. Cell Mol Life Sci57: 224-234.

LIVESEY, F. J. and CEPKO, C. L. (2001). Vertebrate neural cell-fate determination: lessons from the retina. Nat Rev Neurosci2: 109-118.

LUKATS, A., DKHISSI-BENYAHYA, O., SZEPESSY, Z., ROHLICH, P., VIGH, B., BENNETT, N. C., COOPER, H. M.a nd SZEL, A. (2002). Visual pigment coexpression in all cones of two rodents, the Siberian hamster, and the pouched mouse. Invest Ophthalmol Vis Sci43: 2468-2473.

LYALL, A. H. (1957). Cone arrangements in teleost retinae. QJMicrosc Sci98: 189 201.

MA, J., ZNOIKO, S., OTHERSEN, K. L., RYAN, J. C., DAS, J., ISAYAMA, T., KONO, M., OPRIAN, D. D., CORSON, D. W., CORNWALL, M. C., CAMERON, D. A., HAROSI, F. I., MAKINO, C. L. and CROUCH, R. K. (2001). A visual pigment expressed in both rod and cone photoreceptors. Neuron 32: 451-461.

MAKINO, C. L. and DODD, R. L. (1996). Multiple visual pigments in a photoreceptor of the salamander retina. J Gen Physio/108: 27-34.

MALICKI, J. (2000). Harnessing the power of forward genetics-analysis of neuronal diversity and patterning in the zebrafish retina. Trends Neurosci23: $531-541$

MASAI, I., STEMPLE, D. L., OKAMOTO, H. and WILSON, S. W. (2000). Midline signals regulate retinal neurogenesis in zebrafish. Neuron 27: 251-263.

MASLAND, R. H. and RAVIOLA, E. (2000). Confronting complexity: strategies for understanding the microcircuitry of the retina. Annu Rev Neurosci23: 249-284.

MCCABE, K. L., GUNTHER, E. C. and REH, T. A. (1999). The development of the pattern of retinal ganglion cells in the chick retina: mechanisms that control differentiation. Development 126: 5713-5724.

MEARS, A. J., KONDO, M., SWAIN, P. K., TAKADA, Y., BUSH, R. A., SAUNDERS T. L., SIEVING, P. A. and SWAROOP, A. (2001). Nrl is required for rod photoreceptor development. Nat Genet 29: 447-452.

MERBS, S. L. and NATHANS, J. (1992). Absorption spectra of human cone pigments. Nature 356: 433-435.

MILAM, A. H., ROSE, L., CIDECIYAN, A. V., BARAKAT, M. R., TANG, W. X. GUPTA, N., ALEMAN, T. S., WRIGHT, A. F., STONE, E. M., SHEFFIELD, V. C. and JACOBSON, S. G. (2002). The nuclear receptor NR2E3 plays a role in 
human retinal photoreceptor differentiation and degeneration. Proc Nat/ Acad SCi USA 99: 473-478.

MITTON, K. P., SWAIN, P. K., CHEN, S., XU, S., ZACK, D. J. and SWAROOP, A. (2000). The leucine zipper of NRL interacts with the CRX homeodomain. A possible mechanism of transcriptional synergy in rhodopsin regulation. $J$ Biol Chem 275: 29794-29799.

MLODZIK, M. (1999). Planar polarity in the Drosophila eye: a multifaceted view of signaling specificity and cross-talk. Embo J18: 6873-6879.

MOCHIZUKI, A. (2002). Pattern formation of the cone mosaic in the zebrafish retina: a cell rearrangement model. $J$ Theor Bio/215: 345-361.

MORROW, E. M., BELLIVEAU, M. J. and CEPKO, C. L. (1998). Two phases of rod photoreceptor differentiation during rat retinal development. J. Neuroscience 18: $3738-3748$

MÜLLER, H. (1952). Bau und Wachstum der Netzhaut des Guppy (Lebistes reticulatus). Zool Jb63: 275-324.

NAWROCKI, L., BREMILLER, R., STREISINGER, G. and KAPLAN, M. (1985). Larval and adult visual pigments of the zebrafish, Brachydanio rerio. Vision Res 25: $1569-1576$

NEITZ, M. and NEITZ, J. (1995). Numbers and ratios of visual pigment genes for normal red-green color vision. Science 267: 1013-1016.

NEITZ, M. and NEITZ, J. (2000). Molecular Genetics of Color Vision and Color Vision Defects. Arch Ophthalmo/118: 691-700.

NEUMANN, C. J. and NUESSLEIN-VOLHARD, C. (2000). Patterning of the zebrafish retina by a wave of sonic hedgehog activity. Science289: 2137-2139.

NEUMEYER, C., DORR, S., FRITSCH, J. and KARDELKY, C. (2002). Colour constancy in goldfish and man: influence of surround size and lightness. Perception 31: 171-187.

NG, L., HURLEY, J. B., DIERKS, B., SRINIVAS, M., SALTO, C., VENNSTROM, B., REH, T. A. and FORREST, D. (2001). A thyroid hormone receptor that is required for the development of green cone photoreceptors. Nat Genet27: 9498.

NISHIWAKI, Y., OISHI, T., TOKUNAGA, F. and MORITA, T. (1997). Threedimensional reconstitution of cone arrangement on the spherical surface of the retina in the medaka eyes. Zool Sci 14: 795-801.

OTTESON, D. C. and HITCHCOCK, P. F. (2003). Stem cells in the teleost retina: persistent neurogenesis and injury-induced regeneration. Vision Research 43: 927-936.

PACIONE, L. R., SZEGO, M. J., IKEDA, S., NISHINA, P. M. and MCINNES, R. R. (2003). Progress Toward Understanding The Genetic And Biochemical Mechanisms Of Inherited Photoreceptor Degenerations. Annual Review of Neuroscience 26: 657-700.

PERRON, M., KANEKAR, S., VETTER, M. L. and HARRIS, W. A. (1998). The genetic sequence of retinal development in the ciliary margin of the Xenopus eye. Dev Bio/199: 185-200.

PICHAUD, F., BRISCOE, A. and DESPLAN, C. (1999). Evolution of color vision. Curr Opin Neurobio/9: 622-627.

PICHAUD, F., TREISMAN, J. and DESPLAN, C. (2001). Reinventing a common strategy for patterning the eye. Cel/105: 9-12.

RAYMOND, P. A. (1985a). Cytodifferentiation of photoreceptors in larval goldfish: delayed maturation of rods. J Comp Neuro/236: 90-105.

RAYMOND, P. A. (1985b). The unique origin of rod photoreceptors in the teleost retina. Trends Neurosci8: 12-17.

RAYMOND, P. A. (1995). Development and morphological organization of photoreceptors. In Neurobiology and Clinical Aspects of the Outer Retina. M. B. A. Djamgoz, S. N. Archerand S. Vallerga [eds.], London, Chapman \& Hall: 1-23.

RAYMOND, P. A., BARTHEL, L. K. and CURRAN, G. A. (1995). Developmental patterning of rod and cone photoreceptors in embryonic zebrafish. J Comp Neuro/359: 537-550.

RAYMOND, P. A., BARTHEL, L. K., ROUNSIFER, M. E., SULLIVAN, S. A. and KNIGHT, J. K. (1993). Expression of rod and cone visual pigments in goldfish and zebrafish: A rhodopsin-like gene is expressed in cones. Neuron 10: 11611174.

RAYMOND, P. A. and HITCHCOCK, P. F. (2000). How the neural retina regenerates. In Vertebrate Eye Development. M. E. Fini [eds.], Berlin Heidelberg, SpringerVerlag. 31: 197-218.
READY, D. F., HANSON, T. E. and BENZER, S. (1976). Development of the Drosophila retina, a neurocrystalline lattice. Dev Bio/53: 217-240.

REESE, B. E. and GALLI-RESTA, L. (2002). The role of tangential dispersion in retinal mosaic formation. Prog Retin Eye Res 21: 153-168.

REHEMTULLA, A., WARWAR, R., KUMAR, R., JI, X., ZACK, D. J. and SWAROOP, A. (1996). The basic motif-leucine zipper transcription factor $\mathrm{Nrl}$ can positively regulate rhodopsin gene expression. Proc Natl Acad Sci USA 93: 191-195.

ROCKHILL, R. L., EULER, T. and MASLAND, R. H. (2000). Spatial order within but not between types of retinal neurons. Proc Nat/ Acad Sci USA 97: 2303-2307.

ROHLICH, P. and SZEL, A. (2000). Photoreceptor cells in the Xenopus retina. Microsc Res Tech 50: 327-337.

ROHLICH, P., VAN VEEN, T. and SZEL, A. (1994). Two different visual pigments in one retinal cone cell. Neuron 13: 1159-1166.

ROORDA, A. and WILLIAMS, D. R. (1999). The arrangement of the three cone classes in the living human eye. Nature 397: 520-522.

RUBIN, G. M. (1989). Development of the Drosophila retina: inductive events studied at single cell resolution. Cel/57: 519-520.

SASZIK, S., ALEXANDER, A., LAWRENCE, T. and BILOTTA, J. (2002). APB differentially affects the cone contributions to the zebrafish ERG. Vis Neurosci 19: 521-529.

SCHMITT, E. A. and DOWLING, J. E. (1996). Comparison of topographical patterns of ganglion and photoreceptor cell differentiation in the retina of the zebrafish, Danio rerio. J Comp Neuro/371: 222-234.

SCHMITT, E. A. and DOWLING, J. E. (1999). Early retinal development in the zebrafish, Danio rerio: light and electron microscopic analyses. J Comp Neurol 404: 515-536.

SEARS, S., ERICKSON, A. and HENDRICKSON, A. (2000). The spatial and temporal expression of outer segment proteins during development of Macaca monkey cones. Invest Ophthalmol Vis Sci41: 971-979.

STENKAMP, D. L., BARTHEL, L. K. and RAYMOND, P. A. (1997). Spatiotemporal coordination of rod and cone photoreceptor differentiation in goldfish retina. $J$ Comp Neuro/382: 272-284.

STENKAMP, D. L. and CAMERON, D. A. (2002). Cellular pattern formation in the retina: retinal regeneration as a model system. Mol Vis 8: 280-293.

STENKAMP, D. L., FREY, R. A., PRABHUDESAI, S. N. and RAYMOND, P. A. (2000). Function for Hedgehog genes in zebrafish retinal development. Dev. Biol. 220: 238-252.

STENKAMP, D. L., HISATOMI, O., BARTHEL, L. K., TOKUNAGA, F. and RAYMOND, P. A. (1996). Temporal expression of rod and cone opsins in embryonic goldfish retina predicts the spatial organization of the cone mosaic. Invest Ophthalmol Vis Sci37: 363-376.

SWAROOP, A., XU, J. Z., PAWAR, H., JACKSON, A., SKOLNICK, C. and AGARWAL, N. (1992). A conserved retina-specific gene encodes a basic motif/ leucine zipper domain. Proc Natl Acad Sci USA 89: 266-270.

SZEL, A., LUKATS, A., FEKETE, T., SZEPESSY, Z. and ROHLICH, P. (2000). Photoreceptor distribution in the retinas of subprimate mammals. JOpt Soc Am A Opt Image Sci Vis 17: 568-579.

SZEL, A., ROHLICH, P., MIEZIEWSKA, K., AGUIRRE, G. and VAN VEEN, T. (1993). Spatial and temporal differences between the expression of short- and middle-wave sensitive cone pigments in the mouse retina: a developmental study. J Comp Neuro/331: 564-577.

TOHYA, S., MOCHIZUKI, A. and IWASA, Y. (1999). Formation of cone mosaic of zebrafish retina. J Theor Bio/200: 231-244.

TOMLINSON, A. and READY, D. F. (1987). Neuronal differentiation in the Drosophila ommatidium. Dev Bio/120: 366-376.

VAN EEDEN, F. J., GRANATO, M., ODENTHAL, J. and HAFFTER, P. (1999). Developmental mutant screens in the zebrafish. Methods Cel/ Bio/60: 21-41.

VIHTELIC, T. S., DORO, C. J. and HYDE, D. R. (1999). Cloning and characterization of six zebrafish photoreceptor opsin cDNAs and immunolocalization of their corresponding proteins. Vis Neurosci 16: 571-585.

WAN, J. and STENKAMP, D. L. (2000). Cone mosaic development in the goldfish retina is independent of rod neurogenesis and differentiation. J Comp Neurol 423: 227-242.

WÄSSLE, H. and RIEMANN, H. (1978). The mosaic of nerve cells in the mammalian retina. Proc Roy Soc Lond, Series B: Biol Sci200: 441-461. 
WHEELER, T. G. (1982). Color vision and retinal chromatic information processing in teleost; a review. Brain Res Rev 4(2): 177.

WIKLER, K. C., RAKIC, P., BHATTACHARYYA, N. and MACLEISH, P. R. (1997). Early emergence of photoreceptor mosaicism in the primate retina revealed by a novel cone-specific monoclonal antibody. J Comp Neuro/377: 500-508.

WIKLER, K. C., WILLIAMS, R. W. and RAKIC, P. (1990). Photoreceptor mosaic: number and distribution of rods and cones in the rhesus monkey retina. J Comp Neuro/297: 499-508.
WU, D. M., SCHNEIDERMAN, T., BURGETT, J., GOKHALE, P., BARTHEL, L. and RAYMOND, P. A. (2001). Cones regenerate from retinal stem cells sequestered in the inner nuclear layer of adult goldfish retina. Invest Ophthalmol Vis Sci42: 2115-2124.

XIAO, M. and HENDRICKSON, A. (2000). Spatial and temporal expression of short, long/medium, or both opsins in human fetal cones. J Comp Neuro/425: 545-559.

YOKOYAMA, S. (2000). Molecular evolution of vertebrate visual pigments. Prog Retin Eye Res 19: 385-419. 